\title{
Sustainable retailing through omni channel strategy: Dawn of a new era
}

\author{
A. Bharathy* \\ Department of Management, Pondicherry University Community College, Puducherry, India
}

DOI: http://doi.org/10.52814/PJMA.2021.1106

ARTICLE TYPE: Review paper

ARTICLE HISTORY: Submitted: January 2021, Revisions: March 2021, Accepted: March 2021

HOW TO CITE: Bharathy, A. (2021). Sustainable retailing through omni channel strategy: Dawn of a new era. Prayukti - Journal of Management Applications, Vol. 1, Issue 1, pp. 44-50.

*Corresponding author e-mail: bharathyrangan@pondiuni.ac.in

\begin{abstract}
Challenges have been at the forefront of growth and development of human society since time immemorial. In this context Covid 19 posed a very unique challenge that disrupted the entire world, as we live in a flat world today unlike in the past history. The pandemic saw many in the arena of business showing downward surge in growth and even shut shop. Traditional marketing channels be it online or offline were challenged. This saw the rise of omnichannel bridging the gap between them and this is particularly of much concern for business as it has over turned the value delivered through omnichannel shopping for consumers in ways that are sustainable to them. This paper uses a conceptual methodology to obtain insights on the use of omnichannel business model as the dawn of a new era post the pandemic to keep alive our economy's engines of growth.
\end{abstract}

KEYWORDS: Omnichannel, Online stores, Offline stores, Dawn of a new era, Crown shyness.

\section{INTRODUCTION}

"Take the first step in faith. You don't have to see the whole staircase. Just take the first step" said, Martin Luther King Jr. Very true to these words the COVID 19 pandemic made the whole world a dreary place to live in but as in the past there has been hope and bright light. However, the good thing is just as natural disasters like flood, earthquake, volcano and wild fires did damage the ecosystem and kill organisms but have promoted biodiversity and sustainable living. It is a wonder Covid 19 and the quarantine measures in most major cities brought down the pollution. The subprime mortgage crisis during 2007-08 resulted in the enactment of new legislations and an opportunity for people in politics and organizations to relook at their career strategy. September 11, 2001 attack on the twin tower in the US made one to realize the importance of giving and sharing. The Great Depression of 1929-39 resulted massive unemployment and loss of income especially to the industrialized nations of the world but today the world is surely a better place to live in. 
The world of business has seen its share of crisis changing the face of doing business on this planet that we live but surely there was light that made business much better than in the pre-crisis period. In 1985 Coke's move to change its age-old formula was criticized upon and Coke had to go back to its original. They wanted the same old taste and this made Coke to revert back to its old formula. Unilever India after it faced a tough fight for its product Fair and Lovely as it promoted negative stereotypes towards dark skin tones and this didn't deter the company from changing its brand name as Glow \& Lovely and continue its success journey. The Tata Nano car project was shut after the production line started to roll out and suppliers had set up shop around the factory premises at Singur in West Bengal. After bloodshed and death the factory was relocated to Siliguri in Gujarat. Similarly, the Pharma sector answer to Covid 19 is a dawn of a new era indeed. There are a number of case studies of dreary days faced in building up of a brand or company but there was light and resulted in big business empires like Walt Disney, Mc Donalds, Facebook, Google, Apple, Tatas, Birlas, Reliance, Hindujas and more.

It is seen that multitude of innovations rocked the world post Covid right from remote working from home, physical distancing to masks to sanitation tunnel with ultraviolet rays, Covid detection app, mask with antiviral properties, bed made of corrugated box for corona patients in hospital, rising telemedicine, contactless dining, rise of omnichannel marketing, online learning, growth of OTT channels, biometric login to rising online platforms like Zoom, Cisco WebEx and Google meet are indeed a picture of the dawn of a new era that would be a sustainable part of life and business alike.

It is noteworthy to mention the rise of omnichannel and is particularly of much concern for business as it has upturned the value proposition of omnichannel shopping for consumers. A stream of lockdowns resulting in few options for consumers to shop indeed saw that e-commerce provided the needed last mile connectivity for consumers around the globe. Much later today that "early dependence on e-commerce has expanded into a fundamental dependence on still-evolving omnichannel shopping experiences". Despite the fact, that it was not completely born out of the pandemic but has seen a dawn. This global Covid crisis has resulted consumers to adopt both online and offline channels for contactless delivery along with a bouquet of other options that fulfil their purchase needs. And across consumer groups, online channels have become the most crucial shopping bay for "constrained consumers - those whose income and spending have been significantly curtailed or constrained due to unemployment, furloughing or other COVID-19-related challenges". Today, these consumers have evolved as "super users", even if they occasionally purchase from traditional offline stores. This paper is an eye opener as it takes insight from the rise of omnichannel marketing during and post Covid 19 pandemic.

\section{LITERATURE REVIEW}

Covid 19 grounded the normal consumer purchase patterns and it had subsequent impact on even a simple human activity of visiting a neighbourhood grocery store, eating out became a taboo, work moved to home, education was online and a number of manufacturing and retail businesses remained shut. There was a significant shift in demand patterns from offline to online platform globally. In some countries like Italy ecommerce sales went up by $81 \%$ in a week. Covid-19 has caused an "inflection in e-commerce penetration globally driven by consumers' need for safety and convenience and even in India, online is gaining salience". A Bain \& Company-PRICE study of consumers spread in geographically dispersed areas and income ranges during the COVID-19 19 period revealed "about 13\% respondents buying online for the first time, while about $40 \%$ buying more online". This then explains the rise of online shopping/engagement experiences which will be seen for long in the economy. Hence marketers down the line to supply chain operators need to consider strategies that would enable its consumers to satiate their need more safely and effectively as to their advantage. The United States, saw direct to home delivery operators looking other than food, as pharmacies offer prescription-based delivery service on a sample basis, and car dealers provided to offer vehicles to be picked up and dropped off for repair and maintenance. 
Studies show that omnichannel retail is finding increasing adoption in the retail sector (Wang J. et al., 2020). Literature points to omnichannel, as a dynamic option in retail today that "aims to coordinate processes and technologies across supply and sales channels". The concept is still in the beginning as pointed by a research paper (Soroosh Saghiri et al., 2017). This can be related to the impact of Covid 19 in multiple fronts. In India, with mandatory lockdown, all retail shops and the entire modern trade was asked to shut down for more than 2 months, except establishments that sold essential goods. However, according to an estimate from Retail Association of India (RAI), "only 8\% of the retail segment in India sold essential goods" (The Hindu, 2020). This implies that " $92 \%$ of the establishments saw zero sales for close to two months". This saw the "Multi-brand retailers adopting omni - channel - deliver by themselves, or collaborate with other last mile partners". For example, Future Group, made use of its network of Easy Day stores in the Delhi and NCR region to cater to its online grocery orders while Kolkata based Spencer's Retail sought the support of food delivery platform Swiggy, Uber and Rapido to deliver orders placed by customers on its website (Shetty G. et al., 2020). Retail sector consists of multiple segments under it like online retail, essential goods, automobile retail, etc. With varied segments, the impact of COVID - 19 on all these have not been uniform and has been at various levels. National Bureau of Statistics of China (2020) justifies that non-essential segment of retail is being hit the most during the lockdown. The hypothesis of "increase in sales of food grains due to panic buying and increasing e-commerce penetration in retail (e - tail) can be confirmed from their release analysis". While all other retail segments have seen a negative growth rate, "online retail sales of physical goods, Grain and foodstuff, and beverages segment has seen a positive growth rate of 3\%, 9.70\% and 3.10\% respectively". The most impacted retail segments have been automobile, furniture, and garments sans the fashion and textile with the steepest negative growth rate of $-37 \%,-33.5 \%$, and $-30.90 \%$ respectively. Similar trends can be predicted for Indian market as well, except for the beverages segment, which is expected to see a negative growth due to the lockdown orders. A report (India Today, 2020) stated that the automobile industry was one among the top 5 segments calling for urgent support and cooperation amidst the others. Although Covid 19 left no sector unturned, its impact decelerated the growth of industries textile and fashion retail which was already facing stiff competition from countries like Sri Lanka and Bangladesh in terms of cost competitiveness. This industry being the second largest employer next to agriculture affected the 100 million persons employed directly and indirectly in it. Its biggest blow on the segment was looking back from the expected growth rate of $12 \%$ by FY25-26. Hence this paper will explore the rise of omnichannel as a dawn of new era for companies in these segments like automobile, fashion and textile.

\section{OBJECTIVES OF THE STUDY}

The current pandemic and its impact on consumer behaviour and sentiments towards visiting physical stores for purchase of their various product requirements has seen a sea change owing to the need to maintain social distancing, money constraints and other safety norms. The impact has been very severe in the case of purchase of discretionary goods as consumers find them as waste of money that has become dearer and also contactless engagements were seemingly preferred. This study thus tries to explore the changes in consumer attitude and sentiments in the purchase of products like automobile and fashion garments and evaluates the need to adopt a business model like omnichannel marketing.

\section{RESEARCH METHODOLOGY}

A systematic literature review of current developments in the industries facing marketing challenges will provide insight and guide not only prominent studies in areas of potential research interest but also helps us to understand the arrival of new business models to survive post Covid 19. Hence this study would be a qualitative study to spur discussions at a preliminary level and then form the basis for future quantitative studies. 


\section{CASE STUDY DISCUSSION ON ADOPTION OF OMNICHANNEL}

The business world has seen myriad crisis but a few have embraced the dawn of a new era to survive and tell their tales. During first part of 2000, shift from analog to digital photography was a disruption and only a few like Fujifilm successfully transformed the change. This wasn't easy for the company but survival and sustainable growth depended on adoption of new business models. Similarly life over the decades has seen the rise of new models of business operations like "typewriters to Personal computers, video streaming services coming of age over DTH, cable and satellite channels, Wikipedia over encyclopaedia Britannica, Airbnb and Oyo disrupted the accommodation sector leading booking from peer to peer, LEDs (light emitting diode) and CFLs (compact fluorescent lights) dramatically disrupted incandescent light bulbs, iphone revolutionizing what a phone could do with its concept of apps". This pandemic has surely been a catalyst in fast forwarding future through adoption of omnichannel marketing by companies across sectors while in some sectors as identified by the literature review shows that it has been a dawn of a new era post Covid 19 to redeem sales and grow faster.

\section{OMNICHANNEL ADOPTION BY AUTOMATIVE SECTOR}

This industry has been complacent in its distribution channel preference for more than a century while the industry is witnessing changes in competition and technological innovation leading to an empowered consumer. This then calls for exploring new opportunity and building business models that can disrupt the ecosystem to new growth levels. A recent study by Deloitte found that the "most favoured product categories for online purchase preference were electronics, home furnishing and followed by automotive". This will initiate integrated shopping and buying experiences among its consumers. Hence a vertical integration among the manufacturer of original equipment to the dealer close to the consumer need to be designed more closely so that omnichannel customer experience is the maximum. In the case of automobile purchase the traditional purchase behaviour of visiting the brick and motor store to collect information on the competitive products along with test drive was the imminent behaviour observed along the chain leading to final purchase. Though e-commerce model was fast penetrating different industry segments and disrupting consumer purchases, it hardly could have an impact on the automotive sector. Mahindra had ventured much earlier with online offer for KUV500 model but was not convincing to consumers. Further Covid 19 resulted in zero revenue for almost 2 months in this sector and the industry witnessed production cut impacting upon the component industry. Thus the "Micro, Small and Medium Enterprises (MSME)" engaged in the automobile spare parts manufacturing were badly affected. The subsequent lockdowns led to a loss of more than Rs 2,000 crore per day to the automotive sector. A report by (India Today, 2020), top persons in the automobile industry pointed out to downtrend and identified the need to announce revival packages especially those who are at the bottom of thesupply chain. But post Covid the industry was about to experience a magical turnover as consumers started to look for used car dealers as money was becoming dearer to them and slowly as the unlock down gave some economic impetus, the demand shifted to new car demand. But this time the reliance was more on online media for information collection and experiencing the product features through online videos posted by the companies helped in information search much to the scare of Covid preventing visit to physical stores. The early adopters were sure to benefit as the sales started to pick up and then rise while consumers started to adopt the omnichannel mode for the different phases in their purchase cycle. Volkswagen partnered with Nielson and launched new video formats such as bumper ads to boost visibility for its offers and dealerships in cities/suburbs, and it served display ads through Display \& Video 360 to drive in sales.

A study by Capegemini Research Institute (2020) foresees car sales to plunge from 3.4 million units a peak sale witnessed by the sector during 2019 to 2.4 million units during the year ending 2021 taking it to levels of the year 2010. On the other hand, Indian consumers would curtail upon their visits to dealer showrooms and rely more on online interaction. The study points "this preference percentage to be as high of $70 \%$ in India when 
compared to global preference by $46 \%$ ". The sales will be motivated by preference for personal mobility and moving away from shared mobility in the lookout for safety and health. As per KPMG report digital adoption in after-sales service to doorstep pickup or delivery and providing for online payments was observed earlier to the pandemic itself. However, it is interesting to observe the futuristic vision of many manufacturers of original equipment (OEMs) had foreseen the change and were engaging consumers, starting from pre purchase information search to accepting customisation of product features to suit the consumer taste, to order taking, to providing financial services up to delivery in a contact-less way. Even test drives is offered at the customer's doorstep without a visit to showroom.

Further traditional promotional events like "auto car shows and exhibitions" will surely take a backseat for some time now but the online media is sure to be a silver lining amidst the dark clouds.

\section{DAWN OF NEW ERA}

This paper calls the automotive industry to be e future-ready to stay ahead of the curve. As customers are short listing more cars than ever. Many are looking for connected cars, premium top models, and subscription-based services. Preferences are also trending towards contactless engagements. Brands should be ready to meet these needs and create exceptional experiences faster and easier. Though traditional behaviour in purchase will never be completely eliminated the new trend adds value in favour of dealers by reducing their need for highcost rental on showroom space. Hence customer engagement and online experience are the areas of focus in this new battle ground.

\section{OMNICHANNEL ADOPTION BY FASHION AND TEXTILE SECTOR}

Another sector that found hope amidst the gloomy days is the fashion and textile sector. A report from Confederation of Manufacturers Association of India (CMAI), stated that among its 3,500+ members did not have any reserves to pay its employees of over 7 lakh people and had to resort for job cuts with no payment of salary during the peak corona months of April to May. This shut down caused huge impact showing up across every step of the value chain starting from suppliers of fabric material to the suppliers of accessories like zips, labels etc. This means impacting $80 \%$ of MSME in the garment fashion industry. This also affected the garment retailers who had to shut their shops. The fashion garment retail industry was hit to the core as it was no longer a priority purchase and was marked by changes in consumer behaviour patterns and consumer sentiments was to redefine the retail landscape post Covid 19. Nielsen's research has rightly captured the purchase behaviour of consumers subsequent to Covid 19 as described by it at 6 levels. The consumers across the globe have navigated through the first 3 levels of buying characterized as "Proactive healthminded buying, Reactive health management and Pantry preparation". Now they are experiencing the other 3 levels of buying "Quarantine living preparation Restricted living respectively and Returning to normal way of living". Further shopping norms in Covid struck world is encouraging consumers to online shopping and this call the retailers to envision the future that is coming their way. The silver lining in this sector is the online presence which was earlier being used as a key liquidation tool.

Interestingly the online stores started to bridge the gap between the fashion retail companies and consumers as the lockdown started to ease out in phases and consumer sentiment showed reluctance to visit physical stores. This calls for retailers to offer more personalised product experience from search to delivery over and above their competitors in their service bouquet.

Hence, players in the sector should focus on their online engagement and provide superior and competitive services. Some companies like Flipkart, Amazon, Myntra and Ajio have intensified their Omni to use the store networks of various fashion and lifestyle brands for fulfilling consumer orders, accentuated by the pandemic that is changing the way consumers shop. Labels such as "W for Woman, Benetton, Pepe, Jack \& Jones, Inglot, US Polo, Tommy Hilfiger, Calvin Klein and Gap" are currently either piloting or upgrading their 
technologies to bring store inventories on these ecommerce platforms. "Myntra had integrated over 700 stores and plans to expand this to 3,000 stores. Myntra has successfully used the omnichannel model to integrate over 700 stores from more than 70 brands so far. They even intend to launch $150+$ brands from 3,000+ high-street and mall stores in the next six months through omni channel". For years, retailers in India have been merely talking about omnichannel strategies of seamlessly marrying their offerings through both offline and online channels without actually making much progress on the ground. But the pandemic has been a silver lining in disguise.

\section{CONCLUSION \& THE WAY FORWARD}

Despite the easing of curbs this segment grapples with low footfalls in high street stores as the business is linked with social interaction driven by consumers visiting malls, department stores and flagship stores. As the pandemic saw that brands who invested in developing a more customized omnichannel shopping experience to see the "fruits of their labour", a systematic omnichannel strategy will be the way forward in this sector. Technology adoption would be a great way to meet the changing customer sentiments and bring consistency in communication across various digital channels. Adoption of software technologies that can provide integrated solutions in "Supply Chain management, Order to Cash Receipt Management, Financial Management, Credit/Factor Management, Purchasing and Receiving, Production/Import Management, Predictive and Actual Costing and Robust Reporting" would help to provide solution to industries where the product demand is dynamic. Thus virtual presence and providing a strategic engagement online with integrated communication approach and technology adoption will help the sector to face the challenge in the future days.

\section{DRONE USES IN MARKETING CAMPAIGNS}

Just as a canopy of a certain group of trees or a mixed group of trees demonstrate a phenomenon of "crown shyness" - an evolutionary pattern needed for arboreal survival when located in windy areas thereby defending themselves from rubbing each other that may transfer pests or diseases. This survival strategy includes social distancing to longevity. Animals like chimps distance themselves from the one infected so that their community is saved. As do honey bees, bullfrog tadpoles, lobsters, mice and guppies.

As humans we are a more intelligent species and in the wake of the digital revolution sweeping past the consumer behaviour and sentiments the omnichannel strategy is surely the way forward for automobile, fashion and textile industry or any other similar industry that has presence across all touch points apart from their offline stores to every other touch point that consumers endeavour to reach them in their purchase quest. Even though it did not grow out of the pandemic but will disrupt the way businesses reach and engage with consumers over the traditional marketing channels in more sustainable ways.

\section{REFERENCES}

- Auto sales post COVID-19. (2020, June 1). Retrieved January 9, 2021, from KPMG website: https://home.kpmg/in/en/home/insights/2020/06/auto-sales-post-covid-19the-road-to-recovery.html

- Chowdhary, A. (2020, April 20). Can omnichannel retailing be a potential solution to combat COVID-19 crisis? Retrieved January 7, 2021, from Apparelresources.com website: https://apparelresources.com/technology-news/retail-tech/can-omnichannelretailing-potential-solution-combat-covid-19-crisis/

- Forum Gandhi. (2020, April 6). Retail industry will take almost a year to recover from Covid-19 shock. The Hindu Business Line. Retrieved from https://www.thehindubusinessline.com/economy/retail-industry-willtake-almost-anyear-to-recover-from-covid-19-shock/article31271719.ece 
- Hübner, S. (2020, August 7). 20 post-pandemic innovative solutions and products. Retrieved July 1, 2021, from Itonics-innovation.com website: https://www.itonicsinnovation.com/blog/20-post-pandemic-innovative-solutions-and-products

- Kumar, A.; Gawande, A. and Brar, V. (2020). "Neuro-Marketing: Opportunities and Challenges in India". Vidyabharati International Interdisciplinary Research Journal, Vol. 10, Issue 02, June, pp. 214-217.

- Kumar, Girish and Uma, V. R. (2019). "Reinforcing Retail Customer Experience in the Omni Channel World". MERC Global's International Journal of Management. Vol. 7, Special Issue 1, pp. 140-145.

- Overview of textiles industry in India and impact of covid-19. (2020, September 2). Retrieved January 9, 2021, from Televisory.com website: https://www.televisory.com/blogs/-/blogs/overview-of-textiles-industry-in-india-andimpact-of-covid-19

- PTI. (2020, December 15). Lockdown impact: Automotive industry suffered Rs 2,300 crore loss per day, says par panel. Retrieved January 3, 2021, from Economic Times website: https:/economictimes.indiatimes.com/industry/auto/auto-news/lockdownimpact-automotive-industry-suffered-rs-2300-crore-loss-per-day-says-parpanel/articleshow/79742229.cms

- Ramgade, A. and Kumar, A. (2021). "Changing Trends of Hospitality Industry: Emergence of Millennials and Gen Z as Future Customers and their Influence on the Hospitality Industry". Vidyabharati International Interdisciplinary Research Journal. Vol. 12, Issue 01, March, pp. 336-342.

- Retail, E. T. (2020a, April 14). Covid -19 impact: 1 crore job cuts likely in textile industry without govt support, says CMAI. Retrieved July 9, 2021, from PTI website: https://retail.economictimes.indiatimes.com/news/apparel-fashion/apparel/covid-19impact-1-crore-job-cuts-likely-in-textile-industry-without-govt-support-sayscmai/ 75132895

- Retail, E. T. (2020b, August 10). E-commerce revolution in India gets its second wind, post Covid-19. Retrieved January 9, 2021, from ETRetail website: https://retail.economictimes.indiatimes.com/news/e-commerce/e-tailing/e-commercerevolution-in-india-gets-its-second-wind-post-covid-19/77460376

- Rise of omni-channel supply chains. (2017). Retrieved January 9, 2021, from Futurelearn.com website: https://www.futurelearn.com/info/courses/omni-channelretailing/0/steps/78309

- Saghiri, S., Wilding, R., Mena, C., \& Bourlakis, M. (2017). Toward a threedimensional framework for omni-channel. Journal of Business Research, 77, 53-67.

- Shetty, G., Nougarahiya, S., Mandloi, D., \& Sarsodia, T. (2020). COVID-19 and global commerce: An analysis of FMCG, and retail industries of tomorrow. SSRN Electronic Journal. doi:10.2139/ssrn.3603028

- Silver linings amidst the dark clouds. (2020, May 6). Retrieved January 1, 7AD, from Nwnews.com website: https://www.nwnews.com/community/this_week/silverlinings-amidst-the-dark-clouds/article_0cc12f00-a309-58e3-b234-da988ad61775.html

- Taumar, D., \& Auto, E. T. (2020, May 11). Almost 57\% Indian consumers willing to purchase cars in 2020: Survey. Retrieved July 9, 2021, from ETAuto website: https://auto.economictimes.indiatimes.com/news/passenger-vehicle/cars/almost-57indian-consumers-willing-to-purchase-cars-in-2020-survey/75672140

- Total Retail Sales of Consumer Goods Went down by 20.5 percent in the First Two Months of 2020. (2020). Retrieved from http://www.stats.gov.cn/english/PressRelease/202003/t2020s0317_1732694.html

- Wang, J., Zheng, B., \& Liu, H. (2020). Satisfying consumers all around: a multidisciplinary view of omnichannel retail. Industrial Management + Data Systems, 121(1), 158-171. 